\title{
Anglia Ruskin University
}

\section{Disaster resilience: building the jigsaw}

This paper was submitted to Ang lia Ruskin University's Institutional Repository by the author.

Citation: Please cite the published version.

Achour N and Kähkönen, K (2017) (Eds.), Disa ster resilience: building the jigsaw, Intemationa I J oumal of Disaster Resilience in the Built Environment, 8 (3). DOI: https://doi.org/10.1108/l] DRBE-04-2017-0029.

Version: Accepted for public ation

Publisher: Emerald

This a rtic le was published in the Intemational J oumal of Disaster Resilience in the Built Environment (Emerald (02017). This article may be downloaded for personal use only. Any other use requires prior permission of the Publisher. 


\title{
Disaster resilience: building the jigsaw Editorial
}

\author{
Guest Editors: \\ Dr Nebil Achour, Anglia Ruskin University, United Kingdom \\ Kalle Kähkönen, Tampere University of Technology, Finland
}

Disaster resilience deals with strengthening a system's capacity and reliability so that it withstands major external forces and does not fail. Resilient systems are those that have the ability to 'absorb' any shocks they receive during their day-to-day operation. This means that resilience has to deal with the complexity and interconnectivity of the different components of the system and their external connections as part of a fluid day-to-day operating system. In the case of buildings, resilience applies not only to the building's structural components but also the systems that allow it to operate such as roads, electricity, water, and gas networks.

Modern buildings provide more than just shelter. They are expected to address a set of socio-technical criteria that will enable occupiers to be comfortable, safe and develop a sense of belonging to the local environment. A typical modern building is a combination of intertwined systems which do not only depend on each other, but also on external systems such as power, water and gas supplies, road and internet networks. It must have strong structural and non-structural components that will support day to day activities, and withstand hazards to continue operating during a disaster. The design and operation of buildings are now developed by multidisciplinary teams including owners/occupiers, designers, suppliers and managers. Their role is to draw together the bigger picture using their detailed knowledge and expertise. Modern buildings therefore resemble to a jigsaw with complex pieces that need to fit and work together as a cohesive whole, an issue that we try to address in this Special Issue.

This Guest Edited issue promotes this resilience philosophy by selecting relevant papers from the CIB World Building Congress 2016 - Intelligent built environment for life, Theme 5 - Advancing Products and Services - and complementing them with some regular submissions to cover issues that have not been covered at the Conference.

The Conference was held in Tampere, Finland, between 30 May and 3 June 2016. It attracted over 400 papers from academic and professionals from 50 countries. Theme $\checkmark$ aimed at exploring the various needs of modern construction and offering new ways and techniques to address them. More than 200 authors have contributed to the 98 papers included in this volume. The vast majority of this research work is led by 
academics (70 papers) who discuss problems from a theoretical background and suggest solutions; whilst the remaining is led by industry researchers (28 papers) who provide an insight on real life through case studies. Researchers from 28 countries contributed to this Theme representing east and west, north and south of the globe. Papers were classified into 7 categories depending on their topics. Two major lessons to be learned from this body of international research outputs; the first is the need to better integrate design, construction and post-occupancy management in a construction lifecycle specifically with advancement of technology and availability of BIM tools; and the second is the increasing acknowledgment of resilience and sustainability as a major part of modern construction.

A total of 13 papers were included in the "Risk mitigation, resilience and health and safety" category. Amongst these six were about disaster resilience whilst the remainder were about health and safety. Four papers were chosen to be part of this issue. These are:

- "An Investigation on Fire Hazard and Smoke Toxicity of Epoxy FRP Composites" by Saeed Bakhtiyari, Leila Taghiakbari and Masoud Jamali Ashtiani. They investigated fire hazard and smoke toxicity of epoxy FRP composites. Their results suggest that FRP products have dangerous behaviour in fire and potentially contribute to fire growth, and thus a higher level of fire protection might be needed.

- "The Experimental behaviour of CFRP-Strengthened Reinforced Concrete Slabs with Fire Protection Systems Subjected to Standard Fire Exposure" by Saeed Bakhtiyari, Arsalan Kalali, Leila Taghiakbari and Farhang Farhbod. This paper continues the discussion about fire resistance of concrete slabs to highlight that the lack of CFRP fire resistance concrete slabs will potentially fail and that fire protective coating is more likely to protect flat and large surfaces for longer periods.

- "New Demountable Seismic-resistant Joint to Improve Industrial Building Reparability" by Margherita Pongiglione, Chiara Calderini and George Bradley Guy. This paper searches the continuity of social and economic postearthquakes through ensuring that steel warehouses withstand seismic activities by exploring the Design for Disassembly (DfD) approach to complement seismic design and to find a compromise between these two approaches. The study suggests that a compromise between seismic design and DfD is possible and that a metric for assessing DfD steel connections is possible.

- "A Built Asset Management Climate Change Adaptation Model" by Keith Jones, Api Desai, Noel Brosnan, Justine Cooper and Fuad Ali. The authors search asset management adaptation to the climate change through a case study from the UK Social Care sector. The outcome is a 10-point framework for social care landlords to guide them developing a better adaptation plan for their assets. 
The above four papers have been complemented by three papers from regular submissions which were thought fit with the remit of this Guest Edited Issue. These are:

- "Does the Post-disaster Resilient City Really Exist? A Critical Analysis of the Heterogeneous Transformative Capacities of Housing Reconstruction 'Resilience Cells'" by Angeliki Paidakaki and Frank Moulaert. The authors studied advancing resilience by disentangling the contentious interactions of various parameters that define and guide resilience trajectories - such as the physical infrastructure, socio-spatial inequalities, path dependencies, power relationships, competing discourses and human agency. Their findings suggest that the recovery destiny is not predetermined according to pre-set ideas but is moulded by the various bottom-up dynamics who democratically sketch the final socially desirable reconstruction outcome(s).

- "Analysing Community Needs and Skills for Enhancing Disaster Resilience in the Built Environment" by Solomon Babatunde, Srinath Perera and Onaopepo Adeniyi. The authors outlined the needs of communities affected by disasters for the purpose of aligning the needs and skill requirements with the abilities of built environment professionals serving these communities. Their findings suggest that there are five major disaster resilience dimensions: social, economic, technological, environmental and institutional. These dimensions incorporate needs and skills to enhance communities' disaster resilience

- "An Owner-driven Reconstruction in Bihar" by Mittul Vahanvati and Beau Beza. The authors searched the 'key processes' during the owner-driven reconstruction (ODR) process, by implementing agencies, to enhance the longterm disaster-resilience of housing and for community autonomy. Their findings suggest that community mobilisation is one of the key processes that lead to the success of the ODR and its effectiveness on the long-term disaster resilience in Bihar.

The Issue also includes a PhD abstract from the University of New South Wales (Australia) that searched the socio-ecological resilience perspective to enhance hospital service delivery resilience to extreme weather events by Anumitra Vikash Mirti Chand. The research investigated how hospital stakeholders value their built environment as an asset or a liability in responding to extreme weather events (EWEs), how they learn about their built environment in such events and how they transfer these lessons into adaptive strategies to make the built environment more resilient to future EWEs. It promoted a proactive, holistic and systematic approach to health-related disaster and facility management planning in supporting hospital service delivery during EWEs. The study concluded by emphasising the importance of disaster experiences for building resilience and that comprehensive approaches are better ways that reflect the complexity and dynamics of hospitals.

In summary, the key message of this Guest Edited Issue is the need for integrating resilience in all aspects of the built environment system, whether these are part of the socio-technical, design, or operational phases. This integration needs to follow an 
Achour N and Kähkönen, K (2017) (Eds.), Disaster resilience: building the jigsaw, Intemational J oumal of Disaster Resilience in the Built Environment, 8 (3). DOI: https:// doi.org/10.1108/ I] DRBE-04-2017-0029.

adaptive strategy that takes into consideration not only natural but also accidental hazards such as fire, which experience demonstrate can be a major cause of deaths as seen in the 1995 Kobe Earthquake where a large proportion of deaths were related to fire. Finally, it is worth remembering that resilience is similar to a jigsaw with complex pieces that need to fit and work together as a cohesive whole. 